\title{
PENGARUH MOTIVASI TERHADAP PENINGKATAN PRODUKTIVITAS KERJA PEGAWAI PADA KANTOR SAMSAT KABUPATEN SIDRAP
}

\author{
Sri Andayaningsih \\ asriandayaningsih@unismuh.ac.id \\ Fakultas Ekonomi dan Bisnis \\ Universitas Muhammadiyah Makassar \\ Rulianty \\ rulianty@gmail.com \\ Fakultas Ekonomi dan Bisnis \\ Universitas Muhammadiyah Makassar \\ A Arviani Sari \\ aarvianisari@gmail.com \\ Fakultas Ekonomi dan Bisnis \\ Universitas Muhammadiyah Makassar
}

\begin{abstract}
The purpose of this study was to determine the effect of motivation on increasing employee productivity in the Samsat Sidrap District office. The research method uses quantitative methods because the research data are numbers that are processed using spss 20 alerts. With a population of 45 and a sample of 31 respondents the data analysis technique used in this study is simple linear regression with motivation variables $(X)$ and employee performance $(Y)$ ). The results showed that from the simple linear regression that was processed and analyzed using the SPSS method, the equation obtained was $Y=6.592+0.664 X$, where the constant number has a value of 6.592 (positive) stating that if there is no work motivation $(X)$ then productivity work $(Y)$ is 0.664 , meaning that the employee's work productivity is still constant even though work motivation towards Y is zero. If there is a decrease in work motivation, it will reduce the level of employee productivity. So that it can be explained that work motivation has an influence and significant effect on employee work productivity in the Samsat district office
\end{abstract}

Key words : Motivation, Employee work productivity

\begin{abstract}
Abstrak
Tujuan penelitian adalah untuk mengetahui pengaruh motivasi terhadap peningkatan produktivitas kerja pegawai pada kantor samsat kabupaten sidrap. Metode penelitian menggunakan metode kuantitatif karena data penelitian merupakan angka-angka yang diolah menggunakan alikasi spss 20. Dengan populasi 45 dan sampel berjumlah 31 responden teknik analisis data yang digunakan dalam penelitian ini adalah Regresi linear sederhana dengan variabel motivasi (X) dan kinerja pegawai (Y). Hasil penelitian menunjukkan bahwa Dari hasil regresi linier sederhana yang diolah dan dianalisis menggunakan metode SPSS, maka diperoleh persamaannya adalah $\mathrm{Y}=6,592+0,664 \mathrm{X}$, dimana bilangan konstanta mempunyai nilai sebesar 6,592 (positif) menyatakan bahwa jika tidak adanya motivasi kerja (X) maka produktivitas kerja (Y) adalah 0,664, artinya produktivitas kerja pegawai masih tetap walaupun motivasi kerja terhadap Y bernilai nol. Jika ada penurunan terhadap motivasi kerja maka akan menurunkan tingkat produktivitas kerja pegawai. Sehngga dapat dijelaskan bahwa motivasi kerja mempunyai pengaruh dan signifikan terhadap produktivitas kerja pegawai pada kantor samsat Kabupaten Sidrap
\end{abstract}

Kata Kunci: Motivasi, Produktivitas kerja pegawai 


\section{PENDAHULUAN}

Pada suatu perusahaan atau kantor instansi sangat memerlukan sumber daya manusia. Sebab dengan adanya sumber daya manusia suatu perusahaan atau kantor dapat berjalan dengan baik, tetapi suatu perusahaan atau kantor memerlukan sumber daya manusia yang berkualitas agar mampu memberikan hasil yang di harapkan dengan cara memberikan motivasi secara tepat.

Untuk motivasi sumber daya manusia yang tepat digunakan motivasi (alat-alat motivasi) dalam bentuk material insentif yang diberikan berupa uang atau barang yang mempunyai nilai pasar dan dapat memberikan kebutuhan ekonomis, kemudian nonmaterial insentif diberikan seperti pemberian reward, kesejahteraan serta jaminan kesehatan yang tidak ternilai harganya, sehingga memberikan kepuasan atau kebanggaan tersendiri bagi pegawai. Jadi memenuhi kebutuhan ekonomis dan kepuasan atau kebanggan rohani. Dalam penelitian ini penulisan hanya memfokuskan pada alat motivasi dalam bentuk insentif. Sehingga dengan motivasi tersebut dapat memberikan manfaat bagi pegawai dan perusahaan.

Motivasi dalam artikata bagaimana manfaat tenaga kerja dengan memberikan dorongan kerjayang maksimal.Dalam usaha peningkatan produktivitas pegawaimerupakan tanggung jawab setiap perusahaan. Melalui para leader, pegawai berusaha sekuat tenaga dan dengan berbagai cara untuk semakin memaksimalkan potensi pegawai. Mengenai peningkatan produktivitas pegawai bukan monopoli instansi yang mencari keuntungan, melainkan juga merupakan kepentingan organisasiorganisasi yang menjual jasa pelayanan kepada masyarakat.
Sumber daya manusia merupakan hal yang terpenting dalam sebuah instansi.Tercapainya suatu tujan instansi pemerintah tidak lepas dari produktivitas sumber daya manusia di dalamnya.Produktivitas sumber daya manusia ditentukan oleh motivasi kerja sehingga dapat menimbulkan semangat kerja dalam melaksanakan pekerjaan denga baik dan penuh rasa tanggung jawab dengan begitu produktivitas kerja pegawai dapat meningkat dengan maksimal.

Berdasarkan uraian tersebut maka penulis tertarik meneliti :"Pengaruh Motivasi Terhadap Peningkatan Produktivitas Kerja Pegawai Pada Kantor Samsat Kabupaten Sidenreng Rappang".

\section{TINJAUAN PUSTAKA}

\section{a. Pengaertian Manajemen Sumber Daya Manusia}

Teori motivasi mulai dikenal pada tahun 1950-an. Secara khusus, enam teori motivasi dari sudut psikologis, yang dapat diplementasikan dalam manajemen sumber daya manusia di lingkungan suatu organisasi. Teori tersebut adalah Teori Kebutuhan dari Maslow, dalam teori ini kebutuhan diartikan sebagai kekuatan / tenaga ( energy ) yang menghasilkan dorongan bagi individu untuk melakukan kegiatan, agar dapat memenuhi atau memuaskan kebutuhan tersebut. Kebutuhan yang sudah terpenuhi / terpuaskan tidak berfungsi atau kehilangan kekuatan dalam memotivasi suatu kegiatan, sampai saat timbul kembali sebagai kebutuhan baru, yang mungkin saja sama denan yang sebelumnya.

$$
\text { Maslow dalam teorinya }
$$

mengatengahkan tingkat kebutuhan yang berbeda kekuatannya dalam memotivasi seseorang melakukan suatu kegiatan. 
Dengan kata lain kebutuhan bersifat bertingkat, yang secara berurutan berbeda kekkuatannya dalam memotivasi suatu kegiatan, termasuk juga yang disebut bekerja. Urutan tersebut dari yang terkuat sampai yang terlemah dalam memotivasi terdiri dari : kebutuhan fisik, kebutuhan sosial, kebutuhan spiritual, yang sebenarnya cukup penting / dominan peranannya sebagai motivasi, terutama di lingkungan pemeluk suatu agama / kepercayaan pada Tuhan Yang Maha Esa.

\section{b. Pengertian Produktivitas}

Produktivitas mengandung pengertian filosofis, definisi kerja dan yeknik operasional.Secara filosofis, produktivitas mengandung pandangan hidup dan sikap mental yang selalu berubah untuk meningkatkan mutu kehidupan yang pada dasarnya mengembangkan diri dan meningkatkan mutu kehidupan yang pada dasarnya mengembangkan diri dan meningkatkan kemampuan kerja.

Menurut Mochdarsyah Sinungan, dalam bukunya "Produktivitas apa dan Bagaimana" (2005 : 20), menyatakan bahwa produktivitas adalah perbandingan antara totalitas masukan ( input ) selama periode tersebut.

Definisi yang dikeukakan oleh Mochdarsyah tersebut memasukan semua pemakaian factor-faktor produktivitas selama proses produksi hingga selesainya factor-faktor produksi yang dimaksudkan itu terdiri dari tanah, bangunan, peralatan dan tenaga kerja. Banyak faktor yang mempengaruhi produktivitas kerja, baik yang berhubungan dengan tenaga kerja maupun yang berhubungan dengan lingkungan instansi dan kebijaksanaan pemerintah secara keseluruhan.
Menurut kutipan sedaryanti dalam bukunya (2011 : 214), faktor utama yang menentukan produktivitas tenaga kerja, adalah :

1) Sikap serja, seperti : kesediaan untuk bekerja secara bergiliran (ship work) dapat menerima tambahan tugas dan bekerja dalam satu tim

2) Tingkat keterampilan yang ditentukan oleh pendidikan latihan dalam manajemen supervise serta keterampilan dalam teknik industri.

3) Hubungan tenaga kerja dan leader yang tercermin dalam usaha bersama antara pimpinan organisasi dan tenaga kerja untuk meningkatkan produktivitas melalui lingkaran pengawasan mutu.

4) Manajemen produktivitas, yaitu manajemen yang efisien mengenai sumber dan sistem kerja untuk mencapai peningkatan produktivitas.

\section{METODE PENELITIAN}

\section{a. Tempat dan Waktu Penelitian}

Lokasi penelitian merupakan suatu tempat atau wilayah dimana penelitian tersebut akan dilakukan oleh penulis untuk mengambil penelitian dengan mengambil objek penelitian pada kantor Samsat di Kabupaten Sidrap. Adapun waktu yang digunakan dalam penelitian ini selama 2 bulan, yaitu mulai bulan Mei - Juli 2019.

\section{b. Populasi dan Sampel}

Populasi merupakan keseluruhan yang menjadi sumber data dan informasi mengenai sesuatu yang ada hubungannya dengan penelitian tentang data yang diperlukan. Kumpulan subjek atau objek yang akan dikenai generalisasi hasil penelitian ini adalah pegawai yang berada pada bagian pelayanan, dengan jumlah pegawai sebanyak 45 orang. 
Sampel adalah bagian jumlah dan karakteristik yang di miliki oleh populasi tersebut.

\section{c. Instrumen Penelitian}

Dalam penelitian dapat digunakan metode analisis deskriptif yaitu :

1) Analisis kualitatif

Yaitu meode yang digunakan dengan cara menjelaskan beberapa argumentasi yang berkaitan langsung dengan permasalahan. Dalam hal ini, penulis menggunakan beberapa teori atau konsep tentang motivasi dan produktivitas kerja karyawan serta hubungan antara keduanya.

2) Analisis kuantitatif

Dimana dalam penelitian ini dimulai dengan mengumpulkan data dan menyatakan variable-variabel yang menggambarkan presepsi para karyawan terhadapmotivasi serta produktivitas dalam kategori-kategori yang ada pada akhirnya akan menjadii total skor dari pengisisan koesioner oleh responden. Pengisisan koesioner diukur dengan menggunakan skala likert yang terdiri atas (5) sangat setuju, (4) setuju, (3) kurang setuju, (2) tidak setuju, (1) sangat tidak setuju.

\section{d. Metode Analisis}

1) Uji validitas

Uji validitas untuk mengetahui kelayakan butir-butir dalam suatu daftar (konstruk) pertanyaan dalam mendefinisikan variabel. Menilai masing-masing butir pertanyaan dapat di nilai dari nilai corrected item-total correlation. Suatu butir pertanyaan dikatakan valid jika nilai r-hitung yang merupakan nilai dari Corrected ItemTotal Correlation > dari r-tabel yang di peroleh melelui Df (Degree of Freedom). Untuk menguji valid tidaknya pertanyaan dapat di lakukan melalui program komputer Excel Statistic Analisis \&amp; SPSS 22.

2) Uji Realibilitas

Reliabilitas merupakan ukuran suatu kestabilan dan konsistensi responden dalam menjawab hal yang berkaitaan dengan konstruk-konstruk pertanyaan yang merupakan dimensi suatu variabel dan di susun dalam suatu bentuk kuesioner. Alat ukur yang akan di gunakan adalah cronbach alpha melalui program komputer excel statistic analysis \&amp; spss 22 . Reliabilitas suatukonstruk variabel dikatakan baik jika memiliki nilai cronbach alpha , 0,60.6Untuk membuktikan hipotesis yang diajukan, maka penulis menggunakanhipotesis, sebagai berikut:

a) Analisis deskriptif dengan menjelaskan motivasi intensif yang diberikan perusahaan kepada karyawan untuk meningkatkan produktivitas kerja pada kantor Samsat kabupaten Sidrap.

b) Analisis Regresi sederhana digunakan untuk mengetahui pengaruh antara motivasi terhadap produktivitas. Dengan rumus sebagai berikut:

$$
\mathrm{Y}=\mathrm{a}+\mathrm{bX}
$$

Keterangan :

$\mathrm{Y}=$ Produktivitas kerja pegawai

$\mathrm{X}=$ Motivasi

$\mathrm{a}=$ Bilangan kontan

$\mathrm{b}=$ Koefisien regresi

Sumber: Andi. Mappatompo, Ismail Rasulong \&amp; Asdi dalam bukunya SPSS Terapan. 


\section{HASIL DAN PEMBAHASAN}

\section{a. Hasil Penelitian}

Berdasarkan hasil pengumpulan data yang diperoleh melalui penyebaran kuesioner yang diberikan kepada pegawai pada Kantor Samsat Kabupaten Sidrap sebagai responden, maka dapat dieketahui karakteristik setiap pegawai yang dikelompokkan menjadi beberapa kelompok yaitu jenis kelamin responden dan pendidikan responden. Dalam pelaksanaan peneitian ini, ditetapkan sebesar 31 orang responden. Dari 31 kuesioner yang dibagikan kepada responden, semua kuesioner telah dikembalikan dan semuanya dapat diolah lebih lanjut. Oleh karena itu akan disajikan deskripsi karakteristik responden yaitu sebagai berikut :

1) Karakteristik Responden Berdasarkan Jenis Kelamin, adapun karakteristik jenis kelamin pegawai pada Kantor samsat kabupaten Sidrap lebih jelasnya dapat dilihat pada tabel berikut ini:

Tabel 4.1

Jenis Kelamin Responden

\begin{tabular}{||c||c||c||}
\hline Jenis Kelamin & Jumlah & $\begin{array}{c}\text { Persentase } \\
\text { (\%) }\end{array}$ \\
\hline \hline PRIA & 20 & $64,6 \%$ \\
\hline \hline WANITA & 11 & $35,4 \%$ \\
\hline \hline JUMLAH & 31 & $100 \%$ \\
\hline
\end{tabular}

Sumber : Hasil Olah Data Primer, 2019

Berdasarkan tabel 4.1 diatas dapa dilihat bahwa jenis kelamin pria pada Kantor Samsat Kabupaten Sidrap sebanyak 20 orang atau (64,6\%), sedangkan wanita sebanyak 11 orang atau (35,4\%). Jadi yang lebih mendominasi dalam penelitiann ini adalah pria.

2) Karakteristik Responden Berdasarkan Pendidikan

Adapun karakteristik jenis kelamin pegawai pada Kantor samsat kabupaten Sidrap lebih jelasnya dapat dilihat pada tabel berikut ini :

Tabel 4.2

Pendidikan Responden

\begin{tabular}{|c||c||c||}
\hline Pendidikan & Jumlah & $\begin{array}{c}\text { Persentase } \\
\text { (\%) }\end{array}$ \\
\hline \hline SLTA & 8 & $25,9 \%$ \\
\hline \hline D3 & 9 & $29,0 \%$ \\
\hline \hline S1 & 11 & $35,4 \%$ \\
\hline \hline S2 & 3 & $9,7 \%$ \\
\hline JUMLAH & 31 & $100 \%$ \\
\hline
\end{tabular}

Sumber : Hasil Olah Data Primer, 2019

Berdasarkan tabel 4.2 diatas dapa dilihat bahwa pegawai yang pendidikan S1 pada Kantor Samsat Kabupaten Sidrap sebanyak 11 orang atau $(35,4 \%)$, D3 sebanyak 9 orang atau $(29,0 \%)$, SLTA sebanyak 8 orang atau $(25,9 \%)$, sedangkan S2 sebanyak 3 oang atau $(9,7 \%)$. Jadi dapat disimpulkan bahwa jumlah responden terbanyak yaitu berpendidikan S1 sebanyak 11 orang.

\section{3) Deskripsi Tanggapan Responden}

Dalam penelitian ini terdiri dari 2 variabel yaitu variabel independen yaitu Motivasi Kerja (X) dan vaiabel dependen yaitu Produktivitas Kerja (Y). Survey yang digunakan yaitu menggunakan skala likert dimana setiap item diberi skor sesuai yang telah ditetapkan dengan jumlah responden yaitu 31 orang. Adapun 
skor dalam penilaian ini adalah sebagai beikut :
a) Sangat Setuju
diberikan skor 5
b) Setuju
Diberikan
skor 4
c) Kurang Setuju skor 3
d) Tidak Setuju skor 2
e) Sangat Tidak Setuju Diberikan skor 1
Diberikan
Diberikan

Deskripsi responden mengeni pengaruh motivasi kerja terhadap peningkatan produktivitas kerja pegawai pada kantor samsat kabupaten Sidrap dapat dilihat pada tabel berikut :

Tabel 4.3

Deskripsi Variabel Motivasi Kerja (X)

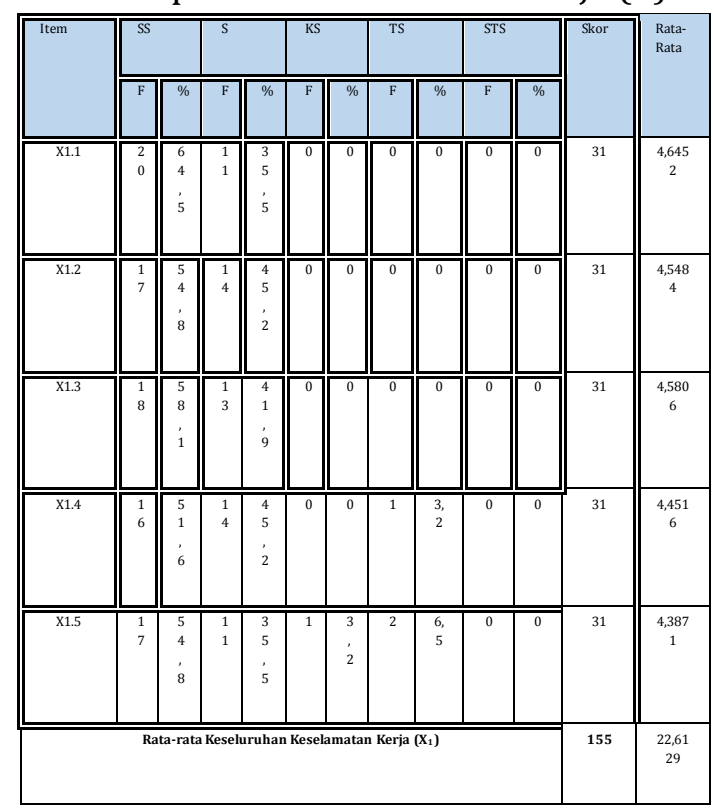

Sumber : Hasil pengolahan data primer, 2019

Berdasarkan tabel 4.3 diatas dari tabel deskripsi variabel motivasi kerja (X) menunjukan sebagian besar responden memilih jawaban sangat setuju yaitu sebesar 31 orang responden. Adanya data ini menunjukkan bahwa motivasi kerja terhadap peningkatan produktivitas kerja pegawai padakantor Samsat Kabupaten Sidrap sudah baik.

Tabel 4.4

Deskripsi Variabel produktivitas kerja (Y)

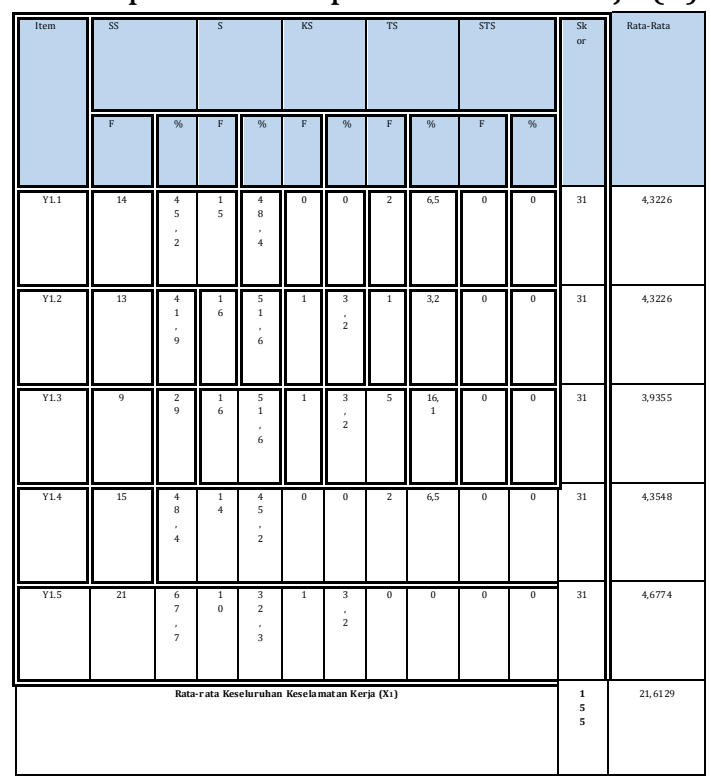

Sumber : Hasil pengolahan data primer, 2019

Berdasarkan tabel 4.4 diatas dari tabel deskripsi variabel produktivitas kerja (Y)menunjukan sebagian besar responden memilih jawaban sangat setuju yaitu sebesar 31 orang responden. Adanya data ini menunjukkan bahwa motivasi kerja terhadap peningkatan produktivitas kerja pegawai padakantor Samsat Kabupaten Sidrap sudah baik.

4) Uji Instrumen Penelitian

\section{a) Uji Validitas}

Uji validitas adalah ukuran yang menunjukkan sejauh mana instrument pengukuran mampu mengukur apa yang ingin diukur. Indikator dikatakan valid apabila pearson correlation lebih dari 0,355 . Berikut pengujian validitas pada variabel Motivasi Kerha (X) dengan menggunakan bantuan SPSS 20. Hasil selengkapnya dapat dilihat pada tabel berikut ini : 
Tabel 4.5

Hasil Uji Validitas Motivasi Kerja (X)

\begin{tabular}{|c|c|c|c|c|}
\hline No & "Keterangan & $\begin{array}{c}\text { Pearson } \\
\text { Correlation } \\
\text { (r hitung) }\end{array}$ & $\begin{array}{c}\mathrm{R} \\
\text { tabel } \\
(\alpha= \\
5 \%)\end{array}$ & $\begin{array}{c}\text { Hasil } \\
\text { Validitas }\end{array}$ \\
\hline 1 & $\mathrm{X} 1.1$ & 0,625 & 0,355 & Valid \\
\hline$\overline{2}$ & X1.2 & 0,366 & 0,355 & Valid \\
\hline 3 & $\mathrm{X} 1.3$ & 0,384 & 0,355 & Valid \\
\hline 4 & $\overline{\mathrm{X} 1.4}$ & 0,613 & 0,355 & Valid \\
\hline 5 & $\mathrm{X} 1.5$ & 0,747 & 0,355 & Valid \\
\hline
\end{tabular}

Sumber : Hasil pengolahan data SPSS, 2019

Berdasarkan tabel 4.5 diatas hasil pengolahan data variabel motivasi kerja (X) menunjukkan bahwa seluruh Pearson Correlation memiliki nilai lebih besar dari $r$ tabel artinya seluruh pernyataan tersebut valid dan dapat dijadikan sebagai alat ukur yang valid dalam analisis berikutnya.

Tabel 4.6

Hasil Uji Validitas Produktivitas (Y)

\begin{tabular}{||c||c||c||c||c||}
\hline \hline No & Keterangan & $\begin{array}{c}\text { Pearson } \\
\text { Correlation }\end{array}$ & $\begin{array}{c}\mathrm{R} \\
\text { tabel }\end{array}$ & $\begin{array}{c}\text { Hasil } \\
\text { Validitas }\end{array}$ \\
& & (r hitung) & & \\
$5 \%)$ & & \\
\hline \hline 1 & Y1.1 & 0,672 & 0,355 & Valid \\
\hline \hline 2 & Y1.2 & 0,435 & 0,355 & Valid \\
\hline \hline 3 & Y1.3 & 0,441 & 0,355 & Valid \\
\hline \hline 4 & Y1.4 & 0,695 & 0,355 & Valid \\
\hline \hline 5 & Y1.5 & 0,481 & 0,355 & Valid \\
\hline \hline & & & & \\
\hline
\end{tabular}

Sumber : Hasil pengolahan data SPSS, 2019

Berdasarkan tabel 4.6 diatas hasil pengolahan data variabel produktivitas kerja (Y) menunjukkan bahwa seluruh Pearson Correlation memiliki nilai lebih besar dari $r$ tabel artinya seluruh pernyataan tersebut valid dan dapat dijadikan sebagai alat ukur yang valid dalam analisis berikutnya.

b) Uji Reliabilitas

Realibilitas adalah ukuran yang menunjukkan konsistensi dalam mengukur gejala yang sama dilain kesempatan. Dimana kuesioner dikatakan reliabel jika nilai Cronbach Alpha lebih besar dari $>0,60$. Hasil uji raliabilitas adalah sebagai berikut :

Tabel 4.7

Hasil Uji Reliabilitas

\section{Reliability Statistics}

\begin{tabular}{|l|l|}
\hline Cronbach's Alpha & N of Items \\
\hline, 708 & 2 \\
\hline
\end{tabular}

Sumber : Hasil pengolahan data SPSS, 2019

Berdasarkan tabel 4.7 diatas bahwa seluruh nilai Cronbach Alpha melebihi nilai Alpha. Karena nilai seluruh Cronbach Alpha lebih besar pada 0,60 maka dapat disimpulkan bahwa seluruh instrument dinyatakan reliabel.

5) Hasil Analisis Regresi Linear Sederhana

Analisis regresi linear sederhana digunakan untuk mengetahui pengaruh motivasi kerja terhadap produktivitas kerja, adapun hasil regresi tersebut dapat dilihat pada tabel berikut ini : 
Tabel 4.8 Coefficients

Hasil Uji Regresi Sederhana

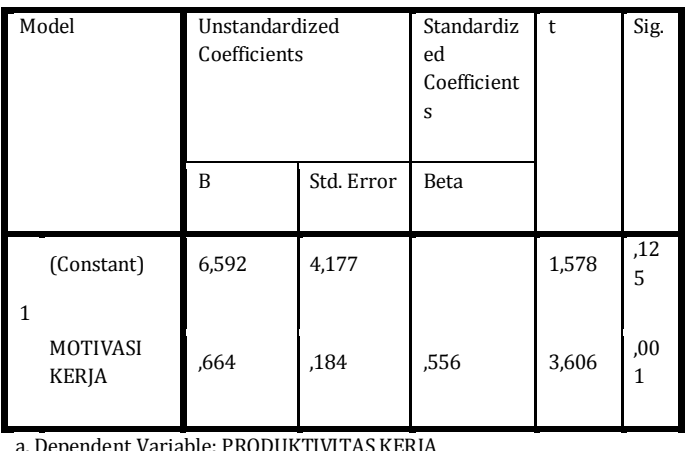

Sumber : Hasil pengolahan data SPSS, 2019

Berdasarkan tabel 4.8 di atas diperoleh koefisien regresi sederhana variabel dengan bantuan program SPSS diperoleh persamaan regresi linear sederhana dapat dituliskan sebagai berikut :

$$
Y=6,592+0,664 X
$$

Bilangan konstanta mempunyai nilai sebesar 6,592 (positif) menyatakan bahwa jika tidak adanya motivasi kerja $(\mathrm{X})$ maka produktivitas kerja (Y) adalah 0,664, artinya produktivitas kerja pegawai masih tetap walaupun motivasi kerja terhadap Y bernilai nol. Jika ada penurunan terhadap motivasi kerja maka akan menurunkan tingkat produktivitas kerja pegawai.

Uji hipotesis bertujuan untuk mengetahui apakah variabel motivasi kerja (X) secara individual/parsial berpengaruh tehadap variabel produktivitas kerja (Y). Kriteria pengujian yang digunakan adalah dengan membandingkan $\mathrm{t}$ hitung dengan $\mathrm{t}$ tabel berdasarkan tingkat signifikan 0,05 dan 2 sisi derajat kebebasan df $(\mathrm{n}-\mathrm{k})=31-1=$ 30 (dimana $\mathrm{n}$ adalah jumlah data dan $\mathrm{k}$ adalah jumlah variabel independen).
Berdasarkan tabel 2.8. Diatas, nilai t tabel adalah sebesar $=2,042$, maka dapat dilihat bahwa t hitung variabel bebas (X) sebesar 3,606 terhadap variabel terikat (Y) adalah sebesar 2,042 hal ini berarti $t$ hitung 3,606 > 2,042, hasil output juga menunjukkan nilai motivasi kerja signifikan 0,001 > 0,05 maka $\mathrm{H}_{1}$ diterima. Berarti ada pengaruh positif dan signifikan motivasi kerja $(\mathrm{X})$ terhadap produktivitas kerja.

Koefisien determinasi

merujuk pada kemampuan variabel independen (X) dalam menerangkan variabel dependen (Y). Komponenkomponen yang terkait dengan koefisien determinasi dapat dilihat pada tabel model summary dibawah ini :

Tabel 4.9

Uji Determinasi $\left(\mathrm{R}^{2}\right)$

\section{Model Summaryb}

\begin{tabular}{|l|l|l|l|l|}
\hline $\begin{array}{l}\text { Mo } \\
\text { del }\end{array}$ & $R$ & $\begin{array}{l}\text { R } \\
\text { Square }\end{array}$ & $\begin{array}{l}\text { Adjusted } \\
\text { R Square }\end{array}$ & $\begin{array}{l}\text { Std. Error } \\
\text { of the } \\
\text { Estimate }\end{array}$ \\
\hline 1 &, $556^{\mathrm{a}}$ &, 310 &, 286 & 1,74126 \\
\hline
\end{tabular}

a. Predictors: (Constant), MOTIVASI KERJA

b. Dependent Variable: PRODUKTIVITAS KERJA

\section{Sumber : : PRODUKTIVITAS KERJA}

Berdasarkan hasil uji koefisien determinasi dari tabel diatas menunjukkan bahwa pada kolom $R$ Square diketahui jumlah persentase total variasi dalam variabel terikat yang diterangkan oleh variabel bebas adalah sebesar 0,310 atau $13,1 \%$. Hal ini berarti besarnya pengaruh variabel bebas (motivasi kerja) terhadap vaiabel terikat (peningkatan produktivitas kerja pegawai) adalah sebesar 13,1\% 
sedangkan sisanya $86,9 \%$ dijelaskan oleh variabel lain di luar penelitian ini.

\section{b. Pembahasan}

Dari hasil penelitian diatas dapat dilihat pengaruh motivasi kerja terhadap produktivitas kerja sangat tinggi artinya variabel motivsi kerja (X) berpengaruh positif/signifikan terhadap produktivitas kerja (Y).yang berarti semakin termotivasi pegawai dalam melakukan pekerjaan maka produktivitas kerja pegawai tersebut tinggi. Sebaliknya jika pegawai tidak termotivasi dalam suatu pekerjaan maka produktivitas kinerja pegawai rendah. Untuk melihat hubungan variabel motivasi kerja $(X)$ dengan variabel produktivitas kerja (Y) dapat dilihat dari nilai t hitung untuk variabel motivasi kerja sebesar 3,606, sementara nilai $\mathrm{t}$ tabel variabel ini pada tabel $5 \%$ sebesar 2,042. Hal ini berarti $t$ hitung 3,606 lebih besar dibanding t tabel 2,042, jadi bisa disimpulkan bahwa variabel motivasi kerja berpengaruh positif dan signifikan terhadap variabel produktivitas kerja.

\section{PENUTUP \\ a. Simpulan}

Penelitian ini bertujuan untuk menguji pengaruh motivasi kerja terhadap produktivitas kerja pegawai pada kantor samsat Kabupaten Sidrap. Dari hasil penelitian ini dapat disimpulkan bahwa Jika ada penurunan terhadap motivasi kerja maka akan menurunkan tingkat produktivitas kerja pegawai. Sehngga dapat dijelaskan bahwa motivasi kerja mempunyai pengaruh dan signifikan terhadap produktivitas kerja pegawai pada kantor samsat Kabupaten Sidrap. Kemudian dari analisis yang dilakukan juga menjelaskan bahwa motivasi kerja dalam kantor berpengaruh positif terhadap pegawai yang bekerja dimana karyawan yang termotivasi selalu mengembangkan pengetahuan dan kemampuan yang dimilikinya untuk meningkatkan produktivitas kerja.

\section{b. Saran}

Berdasarkan hasil penelitian yang diuraikan di atas maka penulis mengajukan saran-saran sebagai berikut :

1) Disarankan kepada kantor agar memaksimalkan motivasi kerja, karena ketika motivasi kerja diberikan dengan baik maka produktivitas kerja karyawan sudah pasti meningkat.

2) Sebaiknya mulai melakukanlah identifikasi akan hal-hal yang dapat meningkatkan motivasi pegawai. Peningkatan motivasi kerja karyawan akan berbanding lurus dengan peningkatan keberhasilan kantor yang tentunya akan diikuti juga dengan peningkatan penghasilan kantor

\section{Daftar Pustaka}

Alimuddin, Ibriati Kartika. 2012. "Pengaruh Motivasi Produksi Kerja Karyawan " skripsi, Makassar : Fakultas Ekonomi dan Bisnis Universitas Hasanuddin.

Andi. Mappatompo, Ismail Rasulong \& Asdi. 2015 . "Spss Terapa". Makassar. Lembaga Perpustakaan dan Penerbitan Universitas Muhammadiyah Makassar

Bangun, Wison. 2012. "Manajemen Sumber Daya Manusia". Jakarta : Erlangga.

Kiki Cahaya Setiawan.2015. "Pengaruh motivasi kerja terhadap kinerja karyawan level pelaksana di devisi operasi PT. Pusri Palembang". Jurnal psikologi islam . vol. 1 no. 2 ISSN 43-53 Http://Scholar.google.co.id. Diakses 27 maret 2019 
Luthfi Parinduri, Yusmartato, Tri Hernawati. 2017. "Pengaruh disiplin dan komitmen terhadap motivasi kerja karyawan di pabrik kelapa sawit ptpn I tanjung seumantoh, Aceh Tamiang".Jurnal teknik industri. Vol. 1 no 4 ISSN 1410 4520. Http://Scholar.google.co.id. Diakses 27 maret 2019

Marwansya. 2016. "Manajemen Sumber Daya Manusia". Bandung : Alfabeta, $\mathrm{cv}$

Multazam. 2005. "pengaruh kesehatan dan keselamatan kerja (K3) terhadap kinerja karyawan pada PT. Semen Tonasa di Kabupaten Pangkep". Makassar : Fakultas Ekonomi dan Bisnis Islam Universitas Islam Negeri Alauddin Makassar.

Mulyadi. 2016. "Manajemen Sumber Daya Manusia". Bogor : IN Media Anggota IKAPI

Nur Amal Karima, Idayanti, Fauziah Umar. 2018. "Pengaruh masa kerja, pelatihan dan motivasi terhadap produktivitas kerja karyawan pada PT. Bank SULSELBAR cabang utama Makassar". Jurnal magister Manajemen Fakultas Ekonomi dan Bisnis vol. 1 no. 4 ISSN 192-211. Http://Scholar.google.co.id. Diakses 27 maret 2019

Priyono \& Marnis. 2014. "Manajemen Sumber Daya Manusia". Sidoarjo : Zifatama Publisher

Saljunuddin, Muhammad Lukman. 2018. "Pengaruh dan pengalaman kerja terhadap Produktivitas kerja Karyawan PT. Comindo Mitra Sulawesi Cabang Palopo". Jurnal Manajemen vol. 4 no. 1 ISSN 23391510. Http://Scholar.google.co.id. Diakses 27 maret 2019

Samsuddin, Harun. 2018. "Kinerja Pegawai". Sidoarjo : Indomedia Pustaka.
Sedaryani. 2011. "Tata kerja dan Produktivitas Kerja". Bandung : Mandar Maju.

Septeria Noor Yuliannisa. 2017. "Pengaruh Kompensasi dan motivasi terhadap produktivitas kerja di PT. Inter pan pasifik futures Banjarmasin". Jurnal ilmu administrasi dan Manajemen vol. 2 no. 1 ISSN 2580-9695.

Http://Scholar.google.co.id. Diakses 27 maret 2019

Sinungan, Muchdarsyah. 2005. Produktivitas : Apa dan Bagaimana. Edisi Kedua. Bumi Aksara

Sutrisno, Edy. 2016. "Manajemen Sumber Daya Manusia". Jakarta : Kencana.

Veithzal, Rivai. 2010. "Manajemen Sumber Daya Manusia Untuk Perusahaan. Dari teori ke Praktek". Jakarta : Rajawali Pers.

Yani. 2012. "Manajemen Sumber Daya Manusia". Jakarta : Mitra Wacana Media.

Yusuf, Burhanuddin. 2015. "Manajemen Sumber Daya Manusia di Lembaga Keuangan Syariah". Jakarta : Rajawali Pers 